\title{
Nuevas publicaciones
}

\section{El portafolio digital como soporte de la práctica reflexiva en la formación docente}

Renata Rodrigues y José Luis Rodríguez-Illera

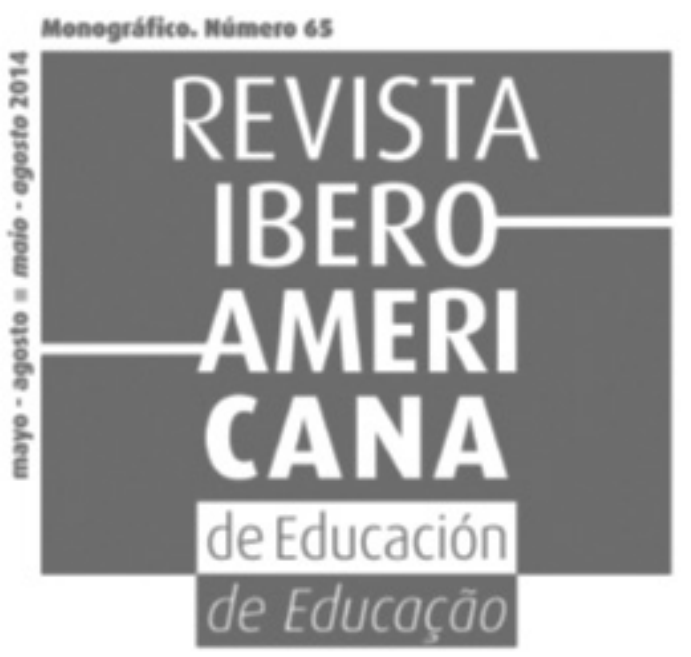

Formación docente continua y nuevas tecnologias. El desafio de cambiar mientras se enseha

Formaçào docente continuo e novos tecnologios. o desafio de mudar enquanto ensino-se

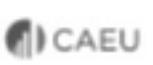

El artículo presenta los resultados de una investigación que analiza el nivel de calidad reflexiva de los profesores, en el marco de un programa innovador de formación docente que introduce la práctica reflexiva, mediada y gestionada a través de un portafolio digital. Aporta a la discusión sobre nuevos usos de un portafolio digital para mejorar los procesos de reflexión por parte del profesorado y sobre modelos alternativos de formación docente; analiza los diferentes niveles de reflexión de los participantes; e identifica los obstáculos para lograr niveles de mayor profundidad. La metodología de investigación adoptada ha sido un estudio instrumental de caso, en el marco de un programa de formación del profesorado universitario. Los resultados obtenidos muestran que

el proceso reflexivo contribuye a una percepción positiva sobre la mejora de su 
desempeño, la planificación de sus clases y una mejor interacción con los alumnos, y que el uso del portafolio digital ha sido bien valorado para el desarrollo del proceso reflexivo propuesto. Asimismo, se identifican carencias, sobre todo en relación con los niveles de profundidad de la reflexión docente. Por último, se presenta una propuesta de indicadores para impulsar y evaluar el desarrollo reflexivo, basada en los hallazgos del estudio.

El artículo puede descargarse libremente del sitio Web de la Revista Iberoamericana de Educación: http://www.rieoei.org/. Busque la siguiente referencia: (2014). Revista Iberoamericana de Educación, (65), pp. 53-74. 


\section{Small Arms Survey 2013: Una amenaza cotidiana. \\ Capítulo 9. Puntos de inflexión: La evolución de las pandillas en Nicaragua}

\section{Dennis Rodgers y José Luis Rocha}

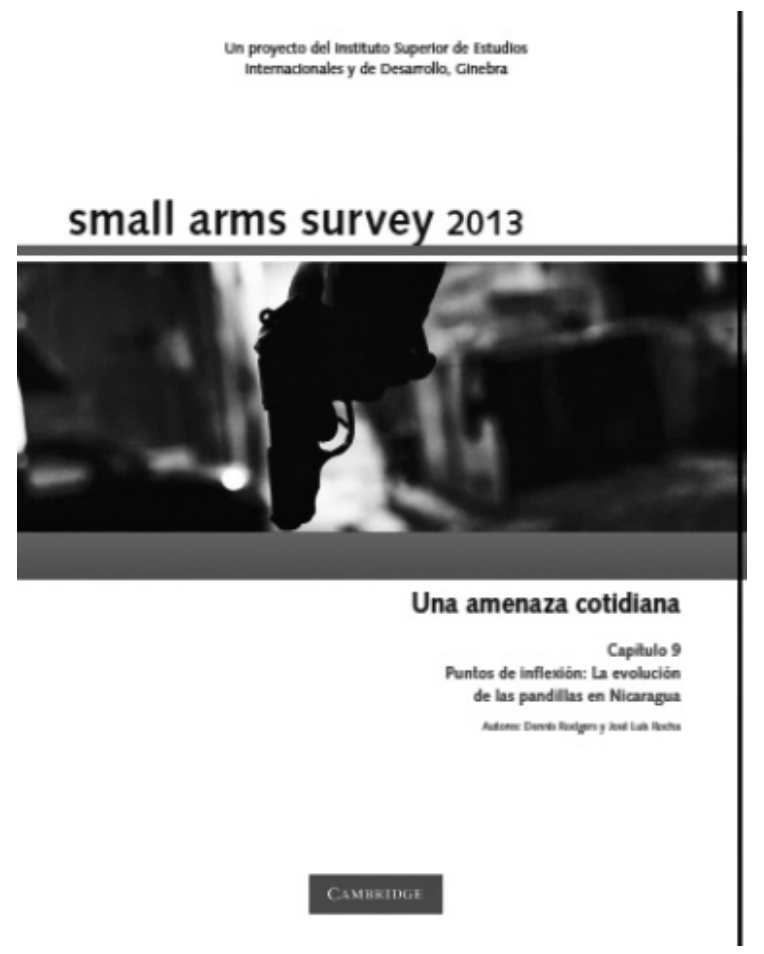

Este capítulo se apoya en un trabajo de campo profundo y de largo plazo con el fin de ofrecer un análisis comparitivo de la trayectoria evolutiva, durante el período posterior a la guerra fría, de las pandillas asociadas a dos barrios de Managua, la capital de Nicaragua: Elías Blanco y Luis Fanor Hernández (estos nombres son seudónimos). Se centra en las tendencias cambiantes en el uso de armas ligeras por parte de los miembros de las pandillas, explorando los diferentes tipos de armas que han usado en diversos momentos de su historia, la naturaleza variable del mercado clandestino de armas, el apogeo y la decadencia de los actores armados, y la evolución constante de la relación entre pandillas y sus comunidades locales.

El capítulo puede descargarse libremente del sitio Web del Small Arms Survey: http:// www.smallarmssurvey.org/ 


\section{Saneamiento en territorios indígenas de Nicaragua: Un proceso en construcción dentro de la Autonomía Regional}

\section{Gema Lorio}

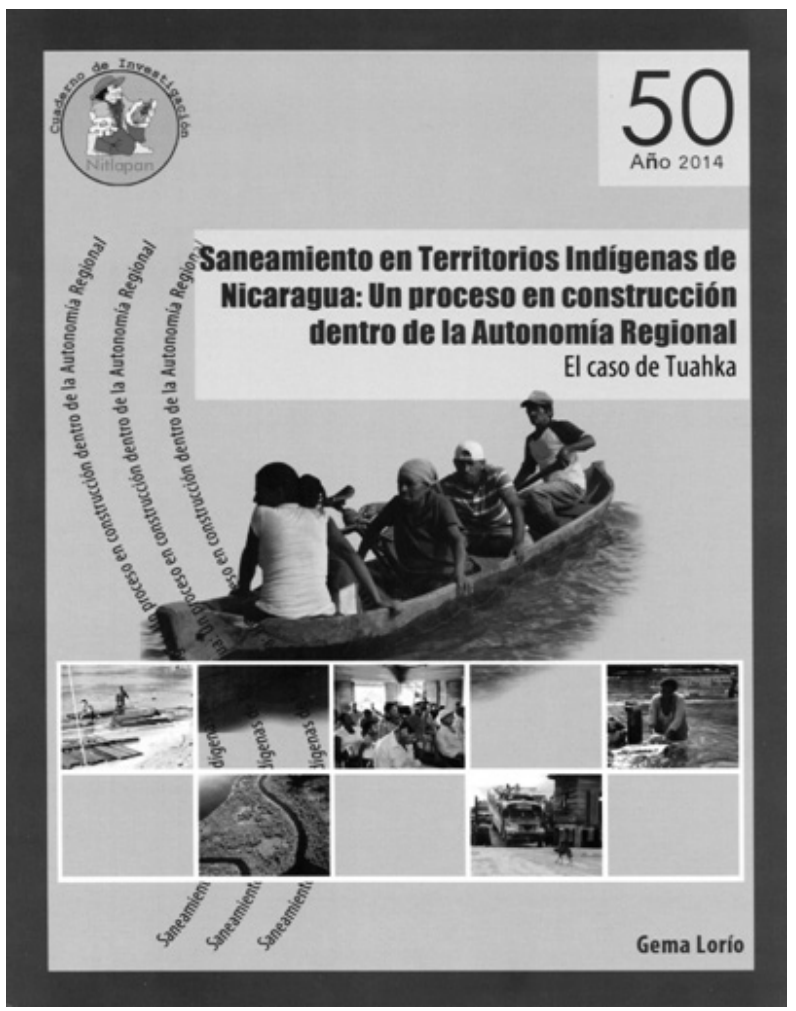

La Investigación aborda la situación de la gobernanza de los recursos naturales, y los procesos de demarcación y titulación en América Latina y Nicaragua. Particularmente hace énfasis en los resultados de un estudio de caso aplicado en un territorio Mayagna (Tuahka) de la Costa Caribe nicaragüense. En éste se presenta el proceso y estrategia que ha seguido el gobierno territorial en relación a la demarcación y titulación de la propiedad.

El cuaderno No. 50 puede descargarse libremente del sitio Web del Instituto Nitlapan de la Universidad Centroamericana: http://www. nitlapan.org.ni/ 
Encuentro №. 98, 68, 2014

\section{Contratos civiles y mercantiles}

Jesús Juseth Herrera Espinoza y Jairo José Guzmán García

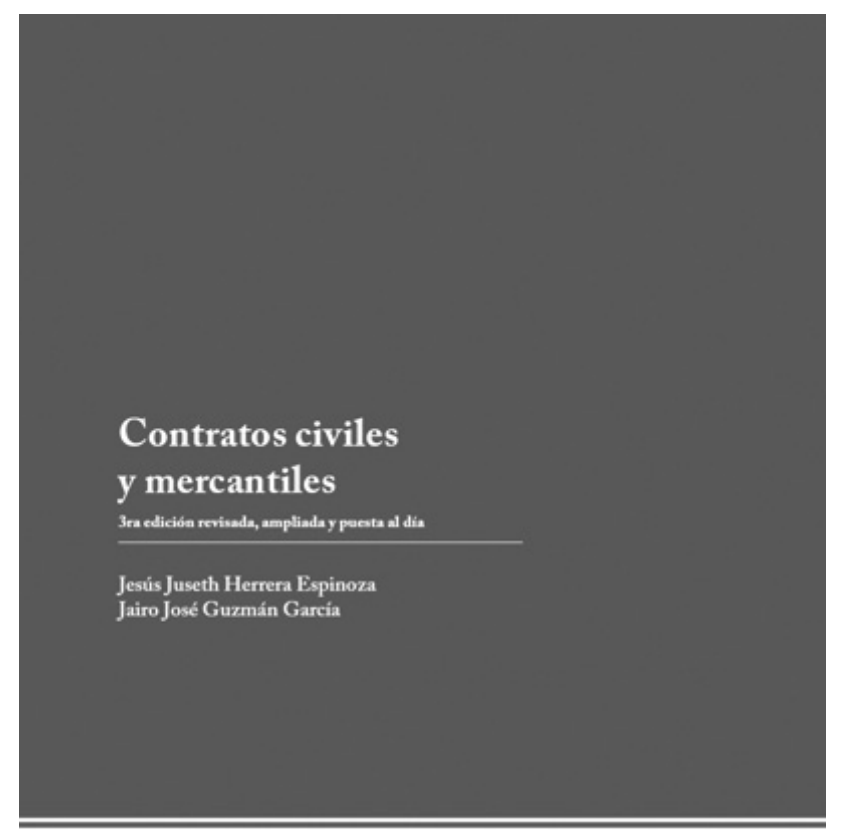

Colección đe Manuales

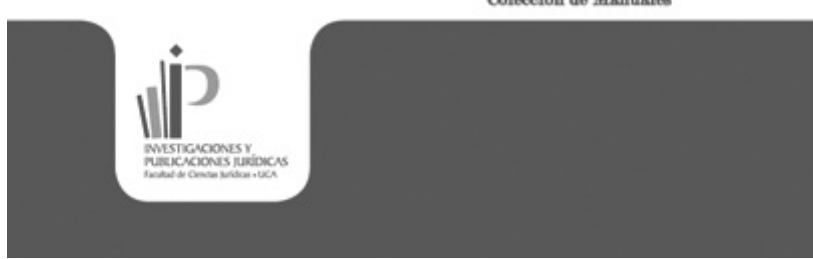

En la tercera edición de "Contratos civiles y mercantiles" los autores han pretendido poner al día la fenomenología contractual tanto en su teoría general como en el desarrollo de los particulares contratos contenidos en los Códigos Civil y Mercantil. En dicha obra se han ajustado, ampliado y mejorado temas que incorporan las nuevas meditaciones que sobre la doctrina se han realizado, ajustándola a su realidad y a la cada vez más cambiante práctica negocial globalizada. 